\title{
Physical Education Teachers' Experiences With Remote Instruction During the Initial Phase of the COVID-19 Pandemic
}

\author{
Kevin Mercier \\ Adelphi University \\ Heather Erwin \\ University of Kentucky
}

\author{
Erin Centeio \\ University of Hawai'i at Mānoa \\ Risto Marttinen \\ George Mason University
}

\author{
Alex Garn \\ Louisiana State University \\ John Foley \\ State University of New York at \\ Cortland
}

\begin{abstract}
This study investigated physical education $(\mathrm{PE})$ teachers' experiences with remote instruction in the United States during the initial outbreak of COVID-19. PE teachers $(n=4,362)$ from all 50 states completed a survey identifying their experiences with remote instruction in May, 2020. Survey responses were analyzed by geographic region, district type, and school level. Teachers reported having students submit assignments (51\% yes), using video instruction (37\% yes), being less effective when instructing remotely (20\% yes), and emphasizing student outcomes focused on health-related fitness ( $32 \%$ yes), and physical activity value/ enjoyment (43\% yes). Access to technology ( $40 \%$ yes) and required student assignments (43\% yes) were lowest among teachers from the South. Rural teachers reported the least access to technology (37\% yes) and rated themselves as least effective (24\% yes). Secondary level teachers reported the highest percentage of required assignments ( $84 \%$ yes). Teachers' responses identify unique challenges to delivering equitable and effective remote PE instruction.
\end{abstract}

Keywords: online teaching, physical activity promotion, youth

In spring 2020, the COVID-19 pandemic forced the majority of school instruction, including physical education (PE) to be delivered remotely. Prior to COVID-19, quality PE programs, whether in-person or remote, exhibited certain characteristics designed to promote student learning outcomes. SHAPE America sees these characteristics as the essential components of PE, which include policy and environment, curriculum, appropriate instruction, and student assessment (SHAPE America, 2015). Research on effective or quality instruction in PE, aligned with student learning outcomes and promoting achievement of standards has been presented (i.e., Rink, 2013). In the United States, National Standards for PE guide programs in helping students meet SHAPE America's stated goal of assisting students in gaining the knowledge, skills, and confidence to enjoy a lifetime of healthful physical activity (PA; SHAPE America, 2013). In-person PE is the context for the overwhelming majority of the research and commentary on effective teaching to promote student learning outcomes.

During the almost overnight switch to remote instruction resulting from the COVID-19 pandemic, in many cases, teachers used trial and error methods in implementing remote instruction (Jeong \& So, 2020). As a marginalized subject area, PE teachers are often left alone to figure out how to implement quality PE without support (Richards, Gaudreault, Starck, \& Woods, 2018). It is reasonable to assume that the pandemic further isolated PE teachers

\footnotetext{
Mercier is with Adelphi University, Garden City, NY, USA. Centeio is with the University of Hawai'i at Mānoa, Honolulu, HI, USA. Garn is with Louisiana State University, Baton Rouge, LA, USA. Erwin is with the University of Kentucky, Lexington, KY, USA. Marttinen is with George Mason University, Fairfax, VA, USA. Foley is with the State University of New York at Cortland, Cortland, NY, USA. Mercier (kmercier@adelphi.edu) is corresponding author.
}

and forced them to make decisions influencing student learning outcomes.

The PE has long been touted as an ideal setting to address public health concerns (Sallis \& McKenzie, 1991; Sallis et al., 2012). Shelter-at-home measures, the closures of gyms and public spaces, and physical distancing measures created new challenges, especially for children, to remain physically active and acquire health-related fitness benefits (Dunton, Do, \& Wang, 2020) aligned with SHAPE America National Standard 3-knowledge and skills to achieve and maintain a health-enhancing level of PA and fitness. PA aids in the prevention of many chronic conditions, including obesity and Type 2 diabetes, that lead to an increased risk of severe infections or mortality associated with COVID-19 (Centers for Disease Control and Prevention, 2020a; Jordan, Adab, \& Cheng, 2020; Sallis, Adlakha, Oyeyemi, \& Salvo, 2020; World Health Organization, 2020). It is important to combat the negative health consequences of physical inactivity and strengthen the immune system by engaging in regular moderate to vigorous PA (Nieman, 2020).

Several of the first reported studies examining the impact of the COVID-19 pandemic on children's PA levels present interesting findings. Short-term studies in the United States and China documented decreased levels of PA during stay-at-home orders and school closures (Dunton et al., 2020; Xiang, Zhang, \& Kuwahara, 2020). A simulation study assessing the impact of school closures and lost PA time in PE projected increases in childhood obesity, with significant race and gender differences, and called for public health interventions (An, 2020). Collectively, these studies, along with the identified benefits of regular PA, strongly suggest a public health need for a focus on children's PA during the COVID-19 pandemic. 
As an often less prioritized subject area (Kougioumtzis, Patriksson, \& Stråhlman, 2011), planning and implementing PE during this pandemic most likely fell to the PE teachers themselves. Though eager to deliver positive experiences, $\mathrm{PE}$ teachers indicated they felt unprepared and desired assistance in learning about best practices for delivering remote instruction (SHAPE America, 2020). Little is known, however, regarding how PE teachers experienced the COVID-19 pandemic-initiated national switch to remote instruction and how these experiences affected PE programs' attempts to deliver effective instruction aimed at positive student learning outcomes.

The purpose of this study was to understand PE teachers' experiences with remote instruction in PE across the United States during the initial outbreak of the COVID-19 pandemic. Specifically, this study investigated whether teachers used assignments, whether students' had access to technology for learning, whether teachers used video for instruction, how effective teachers perceived their remote teaching to be in comparison with their inperson instruction, and which national content standards teachers prioritized. A secondary purpose of the study was to explore associations between these elements of remote instruction and school context characteristics, including grade level, urbanicity, and region of the United States. The term remote instruction will be used in this paper to describe teacher-led PE experiences including virtual lecture or activity classes (synchronous or asynchronous), online assignments (through e-mail or platforms, such as Google Classroom or Blackboard), or hard copy lessons/assignments that were mailed home or picked-up at school.

\section{Method}

A total of 4,362 PE teachers participated in the study with $52 \%$ representing elementary, $25 \%$ secondary, and $23 \%$ reported teaching multilevel. Multilevel was any combination that spanned across both the elementary $(\mathrm{K}-5)$ and secondary $(6-12)$ grade bands. A strong, varied representation of the type of districts that teachers' taught in was reported (urban $42 \%$, suburban $35 \%$, and rural 23\%). Finally, $23 \%$ of teachers taught in the Northeast region of the United States, 25\% in the Midwest, 32\% in the South, and 20\% from the West.

\section{Data Collection}

Secondary data analysis was conducted using data from the Online Physical Education Network (OPEN) www.openphyed.org. Established in March, 2015, OPEN provides free online standards-based PE curricula to meet the needs of physical educators. During the emergence of COVID-19 in the United States, in spring 2020, OPEN provided free weekly PE content for teachers that focused on getting children active while at home. As part of a desire to better understand the needs of the teachers who were using their free resources, OPEN conducted a needs assessment survey in order to guide their content development planning for the start of the school year in the fall. As of May 31, 2020, the OPEN database indicated 83,988 registered users (people who sign up for free access to content and e-mail notices).

Using Google Forms, a link to the survey was distributed in the weekly newsletters with the header "Tell us what you need: Together we will get through this." The link was included in the newsletter for a 2-week period in May, 2020. The users on the OPEN platform consisted of teachers, parents, administrators, higher education faculty, preservice teachers, as well as other groups, but only teachers who identified as teaching PE remotely in a $\mathrm{K}-12$ setting were included for the current study.

The survey did not collect basic demographic data of teachers (i.e., age, gender), as it was developed to better understand how teachers were currently using the curriculum and how OPEN could make improvements in their resources for the future. The survey consisted of items, such as grade level taught, state, type of district, level of teaching, as well as questions that focused on their current remote instruction teaching situation and environment, school's plan for fall 2020, along with teaching and planning priorities. Survey items not aligned with the identified variables of interest were not included in data analysis. Survey items included several types of response options including Likert-type scales, multiple selection, yes/no, and open-ended responses.

Institutional review board approval was received to conduct secondary data analysis from State University of New York at Cortland. Initial deidentified data were downloaded from Google Forms and supplied to the researchers in Google Sheets. Cleaning of data was conducted using gspread (a python application programming interface for google Sheets) and consisted of removing survey responses from those individuals who were not K-12 PE teachers as well as those who started, but did not complete surveys. Data were then downloaded and transferred into Excel. Variables were coded (i.e., categorical or binary) based on purpose and research question. For example, access to technology was given a binary code. Data for the state in which participants taught were categorized by state using the two-letter abbreviation, and then further categorized into four regions based on the Centers for Disease Control and Prevention information for COVID-19 (Centers for Disease Control and Prevention, 2020b).

\section{Data Analysis}

Descriptive statistics were used to provide basic information on independent variables including district type, region, and grade level taught and dependent variables including learning standard priority, submission of assignments, access to technology, use of video, and self-rating of effectiveness. All independent variables were categorical in nature. District type had three levels including rural, suburban, and urban. Region had four levels including Northeast, Midwest, South, and West. Grade level taught had three levels including elementary, secondary, and multilevel (e.g., K-12, $\mathrm{K}-8,6-12)$. Dependent variables were binary except for learning standard priority, which had five classifications (i.e., SHAPE America Standards 1-5) and asked which standards do you prioritize in your remote instruction. Binary codes were as follows: (a) Are your students required to submit any assignments or artifacts of learning? (yes $=1$, no $=0$ ), (b) Do all of your students have access to the technology required to effectively learn in a distance learning environment? (yes $=1$, no $=0$ ), (c) Do you use live or recorded video in your remote teaching? (yes $=1$, no $=0$ ), and (d) How effective has your remote PE teaching been? $(1=$ less effective, $0=$ as/more effective).

We performed chi-square tests in order to test for associations between levels of each independent variable and teachers who prioritized specific national learning standards. Binary logistic regression models were used for the remaining dependent variables. All independent variables were included as predictors using a dummy variable approach in each model (Tabachnick \& Fidell, 2019). We used the Wald test (i.e., unstandardized beta/SE) with an alpha level of .05 to determine statistical significance (Forthofer, Lee, \& Hernandez, 2007). Odds ratios with 95\% confidence 
intervals were used to describe relationships between independent and dependent variables.

\section{Results}

The percentage of "yes" responses for the outcome variables by geographic region, type of school, and level of teaching are presented in Table 1. Nation content standards of priority by region, type, and level are presented in Table 2. Just over half of the teachers suggested they required assignments from their students during the COVID-19 stay-at-home period. Teachers also reported that approximately half of their students had "access to the technology required to effectively learn in a distance learning environment." Only 37\% of teachers reported that students were required to use video for teaching and learning purposes. Despite these barriers, $80 \%$ of the teachers reported their teaching as being "as effective or more effective" during the COVID-19 stay at home period. Finally, a majority of teachers prioritized getting students to value and enjoy PA (SHAPE America Standard 5, 43\%) or develop skills and knowledge related to health-related fitness and healthenhancing PA (SHAPE America Standard 3, 32\%).

Results from the chi-square tests revealed associations between content standards and district type, $\chi^{2}(8)=16.39, p=.04$, grade level taught, $\chi^{2}(8)=156.59, p=.001$, but not region $\chi^{2}$ $(12)=17.21, p=.14$. Urban teachers were more likely than rural and suburban teachers to prioritize Standard 4. Rural teachers were more likely than urban and suburban teachers to prioritize Standard 1 and more likely than urban teachers to prioritize Standard 5. Elementary teachers were more likely than secondary teachers to prioritize Standards 1 and 4; whereas, secondary teachers were more likely than elementary teachers to prioritize Standard 3.

Results from the four binary logistical regression models are presented in Table 3 including unstandardized beta coefficients and odds ratios with $95 \%$ confidence intervals. In Model 1, teachers from secondary schools were 10 times more likely to require assignments compared with elementary teachers. Teachers from the Northeast and from urban schools were also more likely to require their students to turn in assignments. In terms of students having access to technology, suburban school districts, teaching secondary students, or teaching in the Northeast increased the odds of increased access to technology. Urban and suburban teachers were more likely to require use of video. Increased odds of requiring students to use video as part of their PE during the remote instruction was also present for teachers teaching multiple grade levels. Finally, teachers from rural school districts, elementary teachers, and those from Midwest and West regions had greater odds of self-reporting their teaching to be less effective during the stay-at-home period.

\section{Discussion}

The current investigation examined the experiences with remote instruction of PE teachers in the United States during the initial outbreak of COVID-19. The robust and diverse study sample provides information describing how teachers from different types of schools, in different regions, and at different school levels dealt with the challenges of switching to remote instruction during the COVID19 pandemic while attempting to still deliver quality PE. Understanding PE teachers' remote instruction is crucial because it is unclear how long these practices will be in place. Our findings revealed that teachers' remote PE instruction experiences varied by the types of schools they worked in, regions of the United States their schools were located, and the school level they taught. These differences are important to acknowledge and address when attempting to help teachers deliver equitable and effective remote PE instruction.

The PE teachers reported having students submit assignments ( $51 \%$ yes) and using video in their instruction (37\% yes). Online assignment submissions and video instruction within our sample indicate the use of technology in PE during the onset of the

Table 1 Descriptive Statistics for Binary Outcome Variables

\begin{tabular}{|c|c|c|c|c|}
\hline Variable & $\begin{array}{c}\text { Assignments, } \\
\text { yes (\%) }\end{array}$ & $\begin{array}{c}\text { Technology, } \\
\text { yes (\%) }\end{array}$ & $\begin{array}{l}\text { Video, } \\
\text { yes (\%) }\end{array}$ & $\begin{array}{c}\text { Less effective, } \\
\text { yes (\%) }\end{array}$ \\
\hline \multicolumn{5}{|l|}{ Grade level } \\
\hline Elementary & 34 & 45 & 35 & 21 \\
\hline Secondary & 84 & 52 & 38 & 17 \\
\hline Multilevel & 55 & 55 & 42 & 21 \\
\hline Total & 51 & 49 & 37 & 20 \\
\hline \multicolumn{5}{|l|}{ Region } \\
\hline Northeast & 62 & 61 & 41 & 16 \\
\hline Midwest & 52 & 49 & 33 & 24 \\
\hline South & 43 & 40 & 38 & 17 \\
\hline West & 50 & 53 & 36 & 26 \\
\hline Total & 51 & 49 & 37 & 20 \\
\hline \multicolumn{5}{|l|}{ District type } \\
\hline Rural & 50 & 37 & 29 & 24 \\
\hline Suburban & 50 & 63 & 40 & 20 \\
\hline Urban & 53 & 45 & 40 & 18 \\
\hline Total & 51 & 49 & 37 & 20 \\
\hline
\end{tabular}

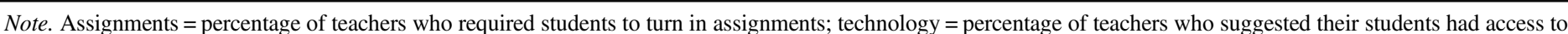

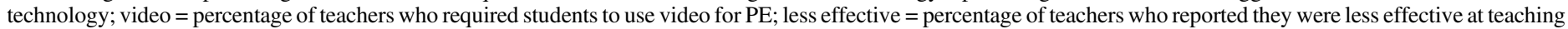
their $\mathrm{PE}$ classes; $\mathrm{PE}=$ physical education. 
Table 2 Descriptive Statistics for Physical Education National Content Standard Prioritization

\begin{tabular}{|c|c|c|c|c|c|}
\hline Variable & Standard $1(\%)$ & Standard $2(\%)$ & Standard $3(\%)$ & Standard $4(\%)$ & Standard 5 (\%) \\
\hline \multicolumn{6}{|l|}{ Grade level } \\
\hline Elementary & 13 & 3 & 28 & 14 & 42 \\
\hline Secondary & 3 & 3 & 42 & 9 & 43 \\
\hline Multilevel & 10 & 4 & 31 & 11 & 44 \\
\hline Total & 10 & 3 & 32 & 12 & 43 \\
\hline \multicolumn{6}{|l|}{ Region } \\
\hline Northeast & 9 & 3 & 30 & 15 & 43 \\
\hline Midwest & 11 & 3 & 33 & 11 & 42 \\
\hline South & 10 & 3 & 32 & 13 & 42 \\
\hline West & 10 & 3 & 33 & 10 & 44 \\
\hline Total & 10 & 3 & 32 & 12 & 43 \\
\hline \multicolumn{6}{|l|}{ District type } \\
\hline Rural & 11 & 2 & 31 & 11 & 45 \\
\hline Suburban & 9 & 4 & 32 & 11 & 44 \\
\hline Urban & 10 & 3 & 33 & 13 & 41 \\
\hline Total & 10 & 3 & 32 & 12 & 43 \\
\hline
\end{tabular}

Table 3 Results From Binary Logistic Regression Models

\begin{tabular}{|c|c|c|c|c|c|c|c|c|}
\hline \multirow[b]{2}{*}{ Variable } & \multicolumn{2}{|c|}{ Mode 1: Assignments } & \multicolumn{2}{|c|}{ Model 2: Technology } & \multicolumn{2}{|c|}{ Model 3: Video } & \multicolumn{2}{|c|}{ Model 4: Less effective } \\
\hline & $b(S E)$ & OR $[95 \% \mathrm{Cls}]$ & $b(S E)$ & OR $[95 \%$ Cls] & $b(S E)$ & OR [95\% Cls] & $b(S E)$ & OR $[95 \%$ Cls] \\
\hline \multicolumn{9}{|l|}{ District type } \\
\hline Urban & $0.18(0.09)^{*}$ & $1.20[1.01,1.42]$ & $0.39(0.08)^{* *}$ & $1.47[1.25,1.73]$ & $0.48(0.08)^{* *}$ & $1.61[1.36,1.91]$ & $-0.10(0.09)$ & $0.90[0.76,1.08]$ \\
\hline Suburban & $0.03(0.09)$ & $1.03[0.86,1.23]$ & $1.13(0.09)^{* *}$ & $3.08[2.60,3.65]$ & $0.48(0.09)^{* *}$ & $1.62[1.36,1.91]$ & $\mathrm{CG}$ & $1.24[1.02,1.51]$ \\
\hline Rural & CG & & CG & & CG & & $0.22(0.10)^{*}$ & \\
\hline \multicolumn{9}{|l|}{ Region } \\
\hline Northeast & $0.67(0.09)^{* *}$ & $1.96[1.64,2.35]$ & $0.78(0.09)^{* *}$ & $2.18[1.84,2.59]$ & $0.09(0.08)$ & $1.09[0.93,1.30]$ & $-0.05(0.11)$ & $0.95[0.76,1.19]$ \\
\hline Midwest & $0.27(0.09)^{* *}$ & $1.32[1.10,1.57]$ & $0.38(0.08)^{* *}$ & $1.46[1.23,1.72]$ & $-0.22(0.08)^{*}$ & $0.81[0.68,0.95]$ & $0.42(0.10)^{* *}$ & $1.53[1.25,1.87]$ \\
\hline South & CG & & $\mathrm{CG}$ & & CG & & CG & \\
\hline West & $0.01(0.10)$ & $1.01[0.84,1.22]$ & $0.47(0.09)^{* *}$ & $1.60[1.34,1.91]$ & $-0.14(0.09)$ & $0.87[0.73,1.04]$ & $0.59(0.11)^{* *}$ & $1.80[1.46,2.22]$ \\
\hline \multicolumn{9}{|l|}{ Grade level } \\
\hline Elementary & CG & & $\mathrm{CG}$ & & $\mathrm{CG}$ & & $0.27(0.10)^{* *}$ & $1.31[1.08,1.60]$ \\
\hline Secondary & $2.31(0.09)^{* *}$ & $10.05[8.36,12.09]$ & $0.22(0.08) * *$ & $1.25[1.07,1.45]$ & $0.13(0.08)$ & $1.13[0.97,1.32]$ & $\mathrm{CG}$ & \\
\hline Multilevel & $0.84(0.08)^{* *}$ & $2.31[1.98,2.70]$ & $0.41(0.08)^{* *}$ & $1.51[1.30,1.76]$ & $0.38(0.08)^{* *}$ & $1.46[1.25,1.70]$ & $0.19(0.11)$ & $1.21[0.97,1.51]$ \\
\hline
\end{tabular}

Note. $b=$ unstandardized beta coefficient; $\mathrm{OR}=$ odds ratio; $\mathrm{CIs}=$ confidence intervals; $\mathrm{CG}=$ independent variable used as the comparison group in dummy variable coding system.

${ }^{*} p<.05 . * * p<.01$.

pandemic. Research prior to the COVID-19 pandemic suggests many PE teachers feel unprepared to use technology (Casey, Goodyear, \& Armour, 2017). In spring 2020, use of technology for remote instruction was, in essence, required for all PE teachers, with little to no time for training. The large number of responses to the OPEN survey, combined with the SHAPE America survey results, where teachers wanted assistance with remote instruction (SHAPE America, 2020) strongly suggests a desire by PE teachers for additional training to become more effective remote instructors. It is important for future research to identify what types of professional development prove successful in training teachers in delivering quality remote PE instruction. This study begins to shed light on the areas in which teachers need additional training as well as where current inequities by school type, region, and level, exist.
Teachers were asked to self-rate their effectiveness when teaching remotely, with the intent of trying to better understand their efficacy toward implementing PE during the pandemic. Only about $20 \%$ of teachers reported that they were less effective teaching students online during the pandemic. We expected this number to be quite higher given the lack of preparedness teachers had in teaching online, coupled with the abruptness of the transition to a remote learning environment. Since this was a self-rated scale item on the survey, it is unknown what criteria teachers were using to measure their own effectiveness. Some interesting and possibly alarming questions, however, remain regarding the goals of PE teachers while teaching remotely. If half of the sample did not use assignments to measure student learning and well over half of the teachers did not use video instruction, what actually occurred in 
these remote PE classes? A larger, and potentially more concerning question is, with little documented instruction and less identified learning, how did $80 \%$ of these teachers rate themselves as being as effective or more effective? Documenting student learning outcomes through assessments is a staple of effective in-person PE teaching (Rink, 2013) and apparently a largely missing component to PE during the onset of the pandemic.

Rural PE teachers reported the least access for their students to technology and rated themselves as least effective in their remote PE teaching. Apparent inequities in these settings led us to believe that children in rural areas received lower quality PE instruction than students in urban or suburban settings. Helping teachers, specifically those in rural settings, develop self-efficacy could aid in improving effective teaching. Teacher efficacy is linked to increased PA for children in PE (Ernst \& Pangrazi, 1999). With a call for public health interventions aimed at increasing PA levels of children during the pandemic (An, 2020) and teachers in the current study identifying SHAPE America National Standard 3 (knowledge and skills to achieve and maintain a health-enhancing level of PA and fitness) as a focus area, it would seem appropriate to develop teacher efficacy to help teachers become more effective in achieving their identified area of focus. Observed decreases in children's PA levels (Dunton et al., 2020; Xiang et al., 2020), the relationship between PA and the severity of COVID-19 complications (Centers for Disease Control and Prevention, 2020a; World Health Organization, 2020), and PE's position as a place to address public health concerns (Sallis et al., 2012) further support increased work on promoting PA levels through remote PE instruction.

Access to technology and the amount of student assignments were the lowest among teachers from the South. In addition, secondary level teachers reported the highest student access to teaching and learning technology and the most student document submissions. Student assessment is a key component of quality PE programs (SHAPE America, 2015) and was not highly documented within our sample, especially at the elementary level. Disparities among these variables, specifically in the South and in rural communities were identified among specific groups. Support, through training and resources, is needed so that all students receive access to quality remote PE instruction. One idea for providing this support would be to make grant funding from state or national associations available for specific groups where disparities were identified. In addition, organizations, such as OPEN, could provide professional development sessions for groups disproportionately affected by changes in PE instruction.

Teachers identified a focus on SHAPE America National Content Standard 3 (maintain a health-enhancing level of PA and fitness) and Standard 5 (recognizes the value of PA for health, enjoyment, challenge, self-expression, and/or social interaction). It appears these two national PE standards were pushed to the forefront and served as prioritized student outcomes. Though the benefits of a focus on Standards 3 and 5 are clear, a sole objective of promoting PA could be too narrow for PE. It is possible that teachers found it easier to have students complete activity logs, report their PA beliefs, and rate their PA affect compared with providing motor skill instruction. As the pandemic, and remote instruction continue, ways to meet all PE goals should be pursued.

\section{Limitations}

One limitation of this study is that the variables measured were collected at one time point during the onset of the pandemic. With a summer to prepare, teachers and schools may have different responses to the questions posed on this survey. It would be beneficial to conduct a follow-up study to see how responses and teachers' experiences changed with more preparation for remote instruction.

Another limitation is that results from the current study rely on the accuracy of teacher self-reporting. Future studies should look to include fidelity measures, such as a student or administrative element, to confirm the presence of findings. A final limitation is that the survey did not ask teachers to identify the types of technology used and needed for student effective remote instruction. Even with the presented limitations and suggestions for future research, the findings from this investigation yield important insights on the initial response to the pandemic from a $\mathrm{PE}$ teacher perspective.

\section{Conclusion}

The experiences of $\mathrm{PE}$ teachers as they switched to remote instruction during the onset of COVID-19 yielded important insights on the short and possibly long-term landscape of PE. Without the ability for physical educators to teach as they had been allowed to teach (i.e., face-to-face, shared equipment, consistent scheduled time), it is essential for teachers to identify alternative strategies to support students' standards-based learning. Without the physical presence of the PE teacher, challenges in guiding students to engage in healthy levels of PA and fitness while fostering student enjoyment of those activities remain. Continued support for PE teachers, through professional development sessions and additional resources, especially among groups where inequities were identified, is needed as teachers adapt to leading students on a new path toward facilitating student learning in PE.

\section{Acknowledgments}

The authors thank OPEN (openphysed.org) for supporting PE teachers and schools throughout the COVID-19 pandemic, collecting data for content development purposes, and sharing the data for this study.

\section{References}

An, R. (2020). Projecting the impact of the coronavirus disease-2019 pandemic on childhood obesity in the United States: A microsimulation model. Journal of Sport and Health Sciences, 9(4), 302-312. PubMed ID: 32454174 doi:10.1016/j.jshs.2020.05.006

Casey, A., Goodyear, V.A., \& Armour, K.M. (2017). Rethinking the relationship between pedagogy, technology and learning in health and physical education. Sport, Education and Society, 22(2), 288-304. doi:10.1080/13573322.2016.1226792

Centers for Disease Control and Prevention. (2020a). Coronavirus disease 2019: People with medical conditions. Retrieved from cdc.gov/ coronavirus/2019-ncov/need-extra-precautions/people-with-medicalconditions

Centers for Disease Control and Prevention. (2020b). Census regional trends for common human coronaviruses. Retrieved from https:// www.cdc.gov/surveillance/nrevss/coronavirus/region.html

Dunton, G.F., Do, B., \& Wang, S.D. (2020). Early effects of the COVID19 pandemic on physical activity and sedentary behavior in children living in the U.S. BMC Public Health, 20(1), 1351. PubMed ID: 32887592 doi:10.1186/s12889-020-09429-3

Ernst, M.P., \& Pangrazi, R.P. (1999). Effects of a physical activity program on children's activity levels and attraction to physical 
activity. Pediatric and Exercise Science, 11(4), 393-405. doi:10. 1123/pes.11.4.393

Forthofer, R.N., Lee, E.S., \& Hernandez, M. (2007). Biostatistics (2nd ed.). Amsterdam, The Netherlands: Academic Press.

Jeong, H.C., \& So, W.Y. (2020). Difficulties of online physical education classes in middle and high school and an efficient operation plan to address them. International Journal of Environmental Research and Public Health, 17(19), 7279. doi:10.3390/ijerph17197279

Jordan, R.E., Adab, P., \& Cheng, K.K. (2020). Covid-19: Risk factors for severe disease and death. British Medical Journal, 368, m1198. doi:10.1136/bmj.m1198

Kougioumtzis, K., Patriksson, G., \& Stråhlman, O. (2011). Physical education teachers' professionalization: A review of occupational power and professional control. European Physical Education Review, 17(1), 111-129. doi:10.1177/1356336X11402266

Nieman, D.C. (2020). Coronavirus disease-2019: A tocsin to our aging, unfit, corpulent, and immunodeficient society. Journal of Sport and Health Sciences, 9(4), 293-301. PubMed ID: 32389882 doi:10.1016/ j.jshs.2020.05.001

Richards, K.A.R., Gaudreault, K.L., Starck, J.R., \& Woods, A.M. (2018). Physical education teachers' perceptions of perceived mattering and marginalization. Physical Education and Sport Pedagogy, 23(4), 445-459. doi:10.1080/17408989.2018.1455820

Rink, J.E. (2013). Measuring teacher effectiveness in physical education. Research Quarterly for Exercise and Sport, 84(4), 407-418. PubMed ID: 24592771 doi:10.1080/02701367.2013.844018

Sallis, J.F., Adlakha, D., Oyeyemi, A., \& Salvo, D. (2020). An international physical activity and public health research agenda to inform coronavirus disease-2019 policies and practices. Journal of Sport and Health Sciences, 9(4), 328-334. doi:10.1016/j.jshs.2020.05.005
Sallis, J.F., \& McKenzie, T.L. (1991). Physical education's role in public health. Research Quarterly for Exercise and Sport, 62(2), 124-137. PubMed ID: 1925034 doi:10.1080/02701367.1991. 10608701

Sallis, J.F., McKenzie, T.L., Beats, M.W., Beighle, A., Erwin, H., \& Lee, S. (2012). Physical education's role in public health: Steps forward and backward over 20 years and HOPE for the future. Research Quarterly for Exercise and Sport, 83(2), 125-135. PubMed ID: 22808697 doi:10.1080/02701367.2012.10599842

SHAPE America. (2013). National standards for K-12 physical education. Reston, VA: SHAPE America.

SHAPE America. (2015). Essential components for teaching physical education. Reston, VA: SHAPE America. Retrieved from https:// www.shapeamerica.org/publications/resources/teachingtools/teacher toolbox/curriculum.aspx

SHAPE America. (2020). Survey results reveal back to school readiness and concerns of nation's health and physical education teachers. Retrieved from https://www.shapeamerica.org/pressroom/2020/Survey_ Results_Reveal_Back_to_School_Readiness_and_Concerns_of_ Nations_Health_and_PE.aspx

Tabachnick, B.G., \& Fidell, L.S. (2019). Using multivariate statistics (7nd ed.). London, UK: Pearson.

World Health Organization. (2020). Q\&A: Be active during COVID-19. Retrieved from https://www.who.int/emergencies/diseases/novelcoronavirus-2019/question-and-answers-hub/q-a-detail/be-activeduring-covid-19

Xiang, M., Zhang, Z., \& Kuwahara, K. (2020). Impact of COVID-19 pandemic on children and adolescents' lifestyle behavior larger than expected. Progress in Cardiovascular Disease, 63(4), 531-532. PubMed ID: 32360513 doi:10.1016/j.pcad.2020.04.013 